a cross-reference for HEEDTA on page 67 should be page 134.

The monograph is an essential aid to all concerned with inorganic analysis in academic and industrial fields and is thoroughly recommended.

G. R. Ramage

\section{EARTH'S MAGNETISM}

\section{Magnetospheric Physics}

(Proceedings of the International Symposium on the Physics of the Magnetosphere, Washington, September 3-13, 1968.) Edited by Donald J. Williams and Gilbert D. Mead. Pp. 459. (American Geophysical Union: Washington, 1969.) $\$ 10$.

THE modern science of geomagnetism dates from 1600 when Queen Elizabeth's physician, William Gilbert, published De Magnete in which he established the concept of the Earth as a magnet. His views of magnetic attraction in terms of action taking place over a distance may well have influenced Isaac Newton, who would undoubtedly have been aware of his suggestion that the planets were held in their courses by magnetic forces.

The idea of an essentially dipolar field, totally arising from sources within the Earth, persisted for almost three conturies, although influences of electric currents flowing externally to the Earth seem to have been first recognized by Carl Friedrich Gauss. In his General Theory of Terrestrial Magnetism published in Leipzig in 1839, Gauss states: "Another part of the theory on which there may exist a doubt is the supposition that the agents of the terrestrial magnetic force are situated exclusively in the interior of the Earth. If we seek for their immediate causes, partly or wholly, without the Earth, and confine ourselves to known scientific grounds, we can only think of galvanic currents. But the atmosphere is no conductor of such currents, neither is vacant space; thus, in seeking in the upper regions for a vehicle of galvanic currents, we go beyond our knowledge. But our ignorance gives us no right absolutely to deny the possibility of such currents; we are forbidden to do so by the enigmatic phenomenon of the Aurora Borealis, in which there is every appearance that electricity in motion forms a principal part."

The concept that the terrestrial magnetic field is modified by an electrically conducting solar wind, which owes much to the scientific contributions (covering half a century) of Sydney Chapman and his colleagues, has been abundantly confirmed through a decade of satellite measurements which commenced with the discovery in 1958 , by J. A. Van Allen, of the trapped belts of energetic particles. We now know in broad outline the configuration of the magnetosphere, which we may define as the region of the terrestrial environment where the magnetic field of the Earth plays a dominant part; it extends some 10 Earth's radii towards the Sun and has an extended "tail" in the anti-solar direction.

The present work has succecded, on the whole, in summarizing the work of this past decade. It contains the fifteen invited review papers presented at the International Symposium on the Physics of the Magnetosphere, held in Washington in September 1968. It is inevitable that, in a field where each new magnetospheric satellite experiment leads to new discovery, the book contains much that is still controversial; nevertheless, it presents between two covers an up to date account of what is known of the physical nature of the magnetosphere and of the dynamical processes which are responsible for it. This involves not only the basic effects of the solar wind interaction, but also phenomena such as the radiation belts, the intimate relation between electromagnetic fields and particles, the aurorae and their associated polar substorms; all of these participate in determining the dynamic equilibrium of the "quiet" magnetosphere and its changes (and their consequences) during solar disturbance events.
While the book admirably serves its purpose of providing a consolidated account of present knowledge, there are two criticisms that might be made. First, although it is, in fact, a reprint of the February/May (1969) issue of Reviews of Geophysics, it would have been appropriate to have added both an author and a subject index. The second is that it might perhaps have been prefaced by an historical review, especially relating to Chapman's outstanding contributions in this field; after all, the symposium was held during Sydney Chapman's 80th year.

\section{T. R. KAISEP}

\section{VOLCANOES AND LANDSCAPE}

\section{Volcanoes as Landscape Forms}

By C. A. Cotton. (Facsimile of the second edition, 1952.) Pp. 416. \$13.50.

\section{Climatic Accidents in Landscape-Making}

By C. A. Cotton. (Facsimile of the 1947 edition.) Pp. $\mathrm{xx}+354+58$ plates. $\$ 15$.

(Hafner: New York and London, 1969.)

THE reprinting of Cotton's well known book on volcanoes supplies a distinct need, for no other work has yet emerged to supplant it. This is the more surprising because volcanoes and vulcanism have excited general interest from earliest times and geologists from the inception of their science; the study of volcanoes has contributed largely to our understanding of earth behaviour, for by comparison with most physical processes, those of vulcanism are rapid and indeed, within certain obvious limits, their operation may be directly observed. Moreover, the destruction or dissection of volcanoes is also rather rapid in terms of geological time, so that we are enabled to appreciate cause and effect more readily than in the case of most phenomena.

Although, as the title indicates, the emphasis of the book is on morphology, the main features of present day volcanic activity in the formation of volcanoes and volcanic fields are also effectively covered. These are essential to an interpretation of older volcanic structures. The first part (60 pages) of the book is devoted to the mechanism of vulcanism with a convenient two-fold division into "lava volcanoes" and "pumice volcanoes"; while all but two chapters of part two (330 pages) which is concerned with volcanic landscapes relates to the constructional aspects of vulcanism. The descriptions cover a wide and very representative range of phenomena.

Perhaps the most serious disability of the book is that the references and consequently the presentation of the subject matter are effectively pre-1944, for, although the second edition appeared in 1952, the modifications made were corrections of detail rather than revision of sub. stance. Some of the more theoretical notions seem, therefore, somewhat obsolescent, if not actually obsolete. In recent years there has, indeed, occurred a revival of interest in interpretation of volcanic phenomena, as distinct from a concern about the petrogenesis of volcanic rocks. Thus, for example, the understanding of volcanic landforms in Iceland where activity has occurred variously in glaciated and non-glaciated conditions; the products of submarine vulcanism and the factors responsible for that diversification; as well as the great elaboration of knowledge on welded tuffs, ignimbrites and mechanisms responsible for their formation have greatly extended the field of enquiry.

Nevertheless, this book provides a very convenient basis of well presented and effectively digested information on volcanoes. It is very readable and it is consistently relevant.

The reprinting of the second book is timely and useful; it provides effective and quite comprehensive accounts of the evolution of landscapes under arid or sub-arid condi- 